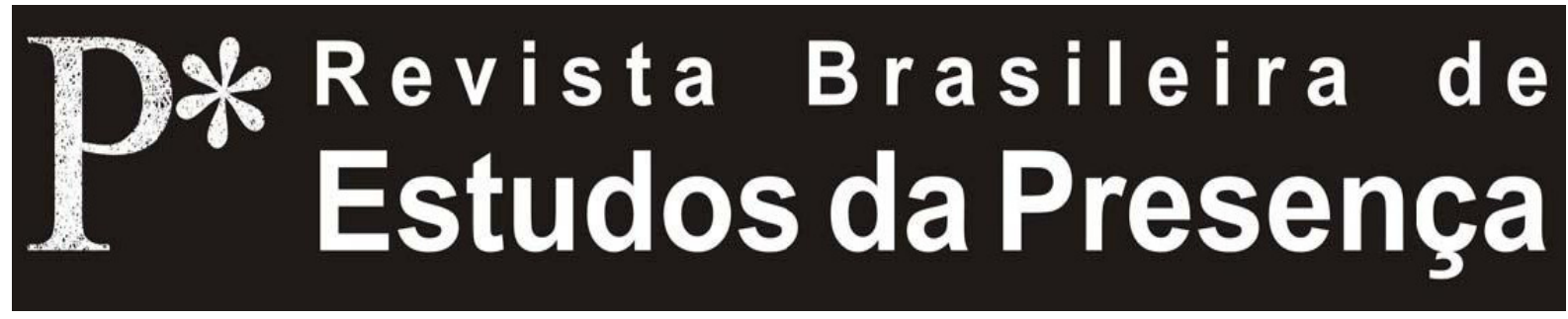

DOI - http://dx.doi.org/10.1590/2237-266036720

ISSN 2237-2660

\title{
"Uma Vida bem Diferente"
}

Resenha sobre a obra

CAMPO, Giuliano; MOLIK, Zygmunt. Trabalho de Voz e Corpo de Zygmunt Molik: o legado de Jerzy Grotowski. Tradução de Julia Barros. São Paulo: É Realizaçóes, 2012. 304 p.

Ricardo Carlos Gomes

Universidade Federal de Ouro Preto - UFOP, Ouro Preto, MG, Brasil

RESUMO - "Uma Vida bem Diferente" - Resenha sobre o livro Trabalho de Voz e Corpo de Zygmunt Molik: o legado de Jerzy Grotowski, composto a partir de entrevistas concedidas por Molik ao pesquisador italiano Giuliano Campo. No livro, o ator e diretor polonês faz uma reflexão sobre sua trajetória artística, pontuada pelas perguntas e observaçóes de Campo. A resenha ressalta os elos entre o trabalho de Molik e a trajetória dos principais artistas do Teatro Laboratório de Jerzy Grotowski.

Palavras-chave: Teatro. Trabalho do Ator. Teatro Laboratório. Jerzy Grotowski. Zygmunt Molik.

ABSTRACT - "A Quite Diferent Life" - Review of Zygmunt Molik's Work on Voice and Body: the legacy of Jerzy Grotowski, a volume developed from Molik's interviews with Italian researcher Giuliano Campo. In the book, questions and comments posed by Campo guide the reflections of the Polish actor and director on his artistic career. The review highlights links between Molik's work and the careers of other leading artists of the Laboratory Theatre of Jerzy Grotowski.

Keywords: Theatre. Actor's Craft. Laboratory Theatre. Jerzy Grotowski. Zygmunt Molik.

RÉSUMÉ - “Une Vie bien Différente” - Cet article propose un résumé critique sur le livre Le travail de Zygmunt Molik sur la Voix et le Corps: l'héritage de Jerzy Grotowski, composé d'entretiens de Molik avec le chercheur italien Giuliano Campo. Dans ce livre, l'acteur et réalisateur polonais mène une réflexion sur sa carrière artistique, ponctuée de questions et commentaires de Campo. Ce résumé critique met en évidence les liens entre le travail de Molik et la trajectoire des artistes les plus importants du Théâtre Laboratoire de Jerzy Grotowski. Mots-clés: Théâtre. Travail de l'Acteur. Théâtre Laboratoire. Jerzy Grotowski. Zygmunt Molik. 
O livro, Trabalho de Voz e Corpo de Zygmunt Molik: o legado de Jerzy Grotowski, é fruto de uma pesquisa teórica e prática de três anos do pesquisador e ator Giuliano Campo sobre o trabalho de um dos fundadores do Teatro Laboratório de Jerzy Grotowski. Composto a partir de entrevistas de Molik concedidas a Campo, faz jus ao legado do grande ator polonês.

Segundo Molik, nos tempos da fundação do Teatro Laboratório, em 1959, quando este, ainda em Opole, chamava-se Teatro das Treze Fileiras ${ }^{1}$, foi ele que, formado pela Academia de Teatro de Varsóvia, assumiu a responsabilidade de trabalhar a voz dos atores: “[...] quando começamos nosso teatro com Grotowski eu já era um tipo de especialista para os outros, sim. Comecei a trabalhar a voz com todo mundo. Sim, esta é a verdade" (Campo; Molik, 2012, p. 39) Com os anos, desenvolveu uma grande competência no trabalho com a voz, sempre em conexão com o corpo, como é evidente no título do livro.

Cheio de informaçóes preciosas sobre os primórdios do Teatro Laboratório, sobre sua evolução, sobre seus diversos integrantes e também sobre o período do Parateatro - sobre o qual são poucas as informaçóes diretas - o livro pode ser uma rica fonte para o pesquisador de teatro. Muitas dessas informaçóes, porém, estão nas entrelinhas do texto e serão percebidas apenas pelo leitor iniciado. Além das referências à relação de Molik com Grotowski, destaco as passagens ligadas a Ryszard Cieslak, que vão desde sua dificuldade inicial no treinamento (Campo; Molik, 2012, p. 39-40) até o reconhecimento de uma relação especial entre e Grotowski e Cieslak:

Sim, me parece que Cieslak era um instrumento genial em que Grotowski pudesse tocar a sua própria Vida enquanto éramos meramente pessoas normais ali. Ele nunca foi tão longe com os outros (Campo; Molik, 2012, p. 83).

Em relação à técnica do ator, há indicações muito precisas como, por exemplo, quando descreve como é possível respirar com todo o corpo (Campo; Molik, 2012, p. 109), mas também passagens até certo ponto surpreendentes, como as declaraçóes sobre a técnica dos ressonadores, que era a base do treinamento vocal dos atores do Teatro Laboratório: "[...] apenas uma coisa secundária, mais externa, não é o objetivo, é muito óbvio. Ressonadores são coisas óbvias" (Campo; Molik, 2012, p. 105) "[...] esqueci dos ressonadores há muito tempo" (Campo; Molik, 2012, p. 37). 
É preciso notar, porém, que uma leitura superficial da descrição e de indicaçóes sobre processos práticos, que devem ser vividos para ser entendidos, tem uma enorme possibilidade de suscitar equívocos. Consciente deste risco, Molik muitas vezes hesita ao tentar descrever elementos de sua prática.

Provavelmente o que estou dizendo parece estranho, mas como posso descrever o Processo? É algo que é pura vida. É a Vida Orgânica em uma forma pura. Não podemos descrever o que está acontecendo nestas circunstâncias e como está transcorrendo. É muito difícil, não tenho um talento descritivo a respeito do que fiz, do que estava fazendo e continuo a fazer (Campo; Molik, 2012, p. 82).

Apesar da consciência dos limites da descrição deste tipo de trabalho prático, há no livro um esforço de conceituação do "Alfabeto do Corpo" - cerca de trinta açóes codificadas por Molik ao longo dos anos, que constituem um tipo de linguagem corporal. Após decorálas, o ator deve "improvisar a Vida com elas" (Campo; Molik, 2012, p. 117). De grande ajuda para compreender esse trabalho, o vídeo Alfabeto do Corpo de Zygmunt Molik (2008), que integra o DVD que acompanha o livro - com o registro das açóes do Alfabeto do Corpo executadas pelo ator português Jorge Parente - é descrito por Molik como "científico" do ponto de vista da direção e "orgânico" na atuação (Campo; Molik, 2012, p. 130)

Ele apenas pensa no que pode ser agora e vai em busca disso. A energia continua. Sim, ele não tem um diploma à toa $^{2}$. Ele é realmente capaz de fazer. Assisti ao vídeo com muito prazer. E na parte da improvisação vocal, fica visível a maneira com que ele acessa o som na base da coluna (Campo; Molik, 2012, p. 124).

Não há como não concordar com Molik, pois Parente executa os diversos "verbetes" do Alfabeto do Corpo com maestria. Para quem souber ver, lá estão todos os detalhes que podem conferir a Vida às açóes do alfabeto. Mais uma vez, porém, muito dependerá da capacidade de olhar do leitor/espectador para captá-los.

O DVD conta ainda com uma galeria de fotos e outros 2 vídeos muito interessantes: Acting Terapy (1976) - que registra uma oficina realizada em Wroclaw na época do Parateatro, com Zygmunt Molik, Rena Mirecka, Antoni Jaholkowski e Stanislaw Scierski como instrutores - e Dyrygent (Maestro) (2006) - que registra uma oficina de Molik em Brzezinka. Os dois momentos mais interessantes de 
Acting Terapy são o processo de trabalho de Molik para "abrir a voz" de um jovem ator e a improvisação final de Rena Mirecka sobre os exercícios plásticos. O canto coletivo final dos alunos é o destaque em Dyrygent.

Outro destaque são os depoimentos de Molik com informaçóes muito relevantes sobre Apocalypsis cum figuris, o último espetáculo da "fase dos espetáculos" do Teatro Laboratório, cujo processo já anunciava a ruptura de Grotowski com a prática teatral que vinha desenvolvendo até então.

Sim, porque ele não sabia nada a respeito. Ele tinha uma ideia, mas não sabia como realizar, enquanto nas apresentaçóes anteriores ele sempre sabia tudo, tudo o que ele queria conquistar com os atores e como diretor. Mas nessa época ele não sabia [...] Todos estavam tentando, olhando ao redor sem nenhuma ideia, e Grotowski ficava apenas sentado e nada, nada acontecia (Campo; Molik, 2012, p. 236).

Suas consideraçóes simples, práticas e precisas sobre o conceito de "verticalidade", ligando-o à voz, que "[...] não é apenas som, não é apenas respiração, mas é também alma [...] sempre caminha de baixo para cima, da base da coluna em direção à cabeça ou ao peito" (Campo; Molik, 2012, p. 177) abrem novas perspectivas de compreensão para o trabalho final da vida de Grotowski, sobre a "Arte como Veículo", quando após abandonar a relação horizontal ator-espectador, concentra-se na verticalidade do Processo no trabalho do ator sobre si mesmo, onde muitas vezes "[...] esse Processo é o elemento mais interessante do trabalho, e é mais importante que o resultado" (Campo; Molik, 2012, p. 179).

Trabalho de Voz e Corpo de Zygmunt Molik: o legado de Jerzy Grotowski é para o leitor a possibilidade de conhecer o ponto de vista de um ator protagonista de uma importante página do teatro do século XX. Nem sempre temos a oportunidade de ouvir a voz dos atores, pois no grupo é o diretor que cria o discurso. Precisamos aproveitá-la, pois a visão do ator é única e singular, uma vez que é seu corpo, sua voz, sua ação, que cria o evento teatral. 


\section{Notas}

${ }^{1}$ Em 1964-1965, quando a Companhia se transferiu para Wroclaw, passou a se chamar "Teatro Laboratório".

${ }^{2}$ Molik refere-se ao "diploma oficial" no qual ele mesmo concedeu a Parente - que ele considerava seu "sucessor" - o "status de Mestre" (Campo; Molik, 2012, p. 119-121).

\section{Referência}

CAMPO, Giuliano; MOLIK, Zygmunt. Trabalho de Voz e Corpo de Zygmunt Molik: o legado de Jerzy Grotowski. Tradução de Julia Barros. São Paulo: É Realizaçôes, 2012. 304 p.

Ricardo Carlos Gomes é ator e diretor, formado na UNIRIO (1987), doutor em teatro pela Università degli Studi di Roma (2007), Professor Adjunto do Departamento de Artes Cênicas da UFOP (desde 2008).

E-mail:diadokai@gmail.com

Recebido em 08 de novembro de 2012 Aprovado em 10 de dezembro de 2012 